\title{
The Need for Employee Education and Training in Macedonian Companies
}

\author{
Prof. Elizabeta Mitreva, $\mathrm{PhD}^{1 *}$, Oliver Filiposki, $\mathrm{PhD}^{2}$, Prof. Nako Taskov, $\mathrm{PhD}^{3}$ \\ University "Goce Delcev" - Shtip, Macedonia, ${ }^{1,2 \& 3}$ \\ 'elizabeta.mitreva@ugd.edu.mk \\ ${ }^{2}$ oliver.filiposki@ugd.edu.mk \\ 3nako.taskov@ugd.edu.mk
}

*Corresponding author

\begin{abstract}
This paper shows the results obtained on the basis of research in the Macedonian companies whether they are committed to training and development of its employees; is the top management willing to improve the knowledge and skills and to transfer that knowledge onto the employees which is the basis for continuous improvement of quality. The results of this research has shown the need of creating a methodology for organizational education as part of the overall methodology for the design and implementation of TQM (Total Quality Management) in companies that should help them enhance the quality of work and their business performance.
\end{abstract}

Keywords- quality system; organizational learning; TQM; model; innovation

\section{INTRODUCTION}

Organizational learning is an integral part of TQM strategy because if you do not learn new techniques and methods there is no possibility for progress and development. Knowledge strengthens the competitive advantage of the companies. An important role plays the top management which should always be ready to learn and serve as an example for the rest of the employees. Learning is an introduction into the overall quality management. Introduction, because you need to gain the necessary knowledge for the quality to be able to project the quality system. It is important to continuously improve the employee standards and encourage training and development of employees, in that way the company will also progress and learn and be able to offer better conditions for its employees.

\section{REVIEW OF LITERATURE}

Organizational learning is an integral part of total quality management process as if you do not learn new techniques and methods there is no possibility for progress and development.

As per Chepujnoska and Chepujnoski (1993)[2] only those who are constantly learning and progress have a chance to succeed. The educational process is continuous and applies to all employees in terms of their work. To achieve the goal you need at least $70 \%$ of employees to master the way of quality.

Deming (2000)[17] in its 14-point program for quality management reserve item 6 to point out the importance of training for each position; in paragraph 13 is mentioned development of an intensive program for education and self-improvement. Training is crucial tool for continuous improvement through constant strengthening of the ability of all employees, from the doorman to the manager. Knowledge strengthens the competitive advantage of the organization.

Everyone need to learn because in that way each employee can easily solve the problems (Garavan, 1991)[9]. Quality management is based on teamwork, only with the necessary knowledge everyone can be creative and contribute to increasing the quality of work and results of the organization. Learning creates and strengthens the team spirit, knowledge leads to understanding, trust and culture of behavior and work. Individuals and experts, on their own, cannot influence the improvement of quality if everyone else does not contribute.

Investing in technology, equipment and changes in processes is important, but those inputs do not guarantee the development of operation and advantage over competitors without adequate investment in staff. The most developed and richest countries in the world base their strategy on the development of industry knowledge and invest in it.

For many authors (Teare \& Dealtry, 1998[21]; Raidén \& Dainty, 2006[16]; Jashapara, 2003[10]; Robertson \& O'Malley Hammersley, 2000)[17] modern trends in management move in direction where employees no longer receive simple standards and methods, but tasks with goals, while they are free to choose how they will accomplish that goal.

This requires higher level of education and training, development of the individualism, especially proactive 
management in participation and realization of the set goals.

In modern society, knowledge according to Drucker (2014)[4] is a strategic source of power and wealth, and everyone in the society befits from it. It is about people who are able to put knowledge in function of performing the business activities and they are called workers of knowledge.

Competitive advantage of the organization for Senge (2014)[19] is its ability to learn faster than competitors, and for that to happen, the effectiveness of the entire organization must be greater than the effectiveness of its respective departments put together.

Davenport and Prusak (1998)[5] believe that knowledge in organizations is a fluid mix of different experiences, values, environmental information, expert's insight that provides assessment and acceptance of new knowledge and information. These authors believe that in the global economy, knowledge can be the biggest asset of the company.

The advantages of learning organization according to Mumford (2004)[14] are: ensuring long-term success of the organization; permanent improvements are becoming practice; incensement of creativity, innovation and adaptation; attracting people who want to succeed and learn, and retain them in the organization; the organization is confident that staff are trained to meet the current and future needs.

Experts today write and speak about an organization that learns or "learning organization", according to Drew and Smith (1995)[6]. In the broadest sense, the learning organization is consist of employees who have mastered the corporate processes of continuous creation, retention and encouragement of individual and collective learning, to be able to advance the results of the organization in a way that is relevant to all users in terms of continuous improvement of the operation and results of the organization.

Without human potential the capital has no worth. The potential for Kaplan and Norton (2004)[17] should be developed and if the organization invests in it, success will follow. Kaplan and Norton believe that human resources potential along with the culture of the organization are worth more than the tangible capital.

Therefore, people are an important source of sustainable competitive advantage. The development of sustainable competitive advantage of a company is directly correlated with the resources and capacities, especially business potential of management teams composed of their knowledge, skills, inventiveness, leadership, and other elements necessary to deal with the changes and produce measurable results (Symes \& McIntyre, 2002[18]; Prodanovska \& Mitreva, 2009[15]; Taskov \& Mitreva, 2015)[20].
Edwinsson and Malone (1997)[7] consider that there is a new commercial reality called economy of knowledge that changes the current concept of values. If the organization strives for success, it is necessary to create a recipe for knowledge and to have sustainable development. It further states that intellectual capital is the future of all activities and that only with it the potential energy of an organization can be measured, and without investment in intellectual capital there is no innovation, nor development of the company.

\section{METHODS IN THE RESEARCH AND ANALYSES OF THE RESULTS}

The subject of interest in this study is an analysis of Macedonian companies in terms of whether they are learning organizations. Special attention was made to the research of the ability of companies to overcome the common processes of continuous creation, retention and encouraging individual and collective learning that would be used to advance the results of the organization. According to the previously defined goals of this empirical research, the list of surveyed companies consisted of 3109 Macedonian companies. The research was conducted in cooperation with the Chamber of Commerce of the Republic of Macedonia. In the process of analysis actively participated only 363 companies and managers from their respective quality control departments. When choosing the sample selection a special attention was made to analyses companies that have established quality system on one side and those who do not have on the other, as well as to determine the differences between them. The research was based on questionnaire and a detailed study of the companies conducted by the research team. Although, it was planned many Macedonian companies to participate, the research was realized with participation of only 363 companies which is $11.6 \%$ of the estimated database, such a response is typical for this type of research (Bohdanowicz 2005a[1]; Medina-Munoz Garcia-Falcon 2000)[13]. These criteria are used to evaluated whereabouts of Macedonian companies and to identify the large gap between local and developed European and global companies as well as their ability to compete on the global market. Due to great quantity of investigated material this study only shows the results in terms of weather Macedonian companies are learning, is the top management ready to learn and serve as an example for the other employees to be inspired to learn.

The structure of the surveyed companies - participants in the survey, as per the industries to which they belong (National Classification of Activities - NKD rev. 2 ("Official. Gazette of the Republic of Macedonia" no. 147/08) and amendment of the National Classification of Activities - NKD Rev. 2 in place since 1 January 2013) is shown in Figure 1. 


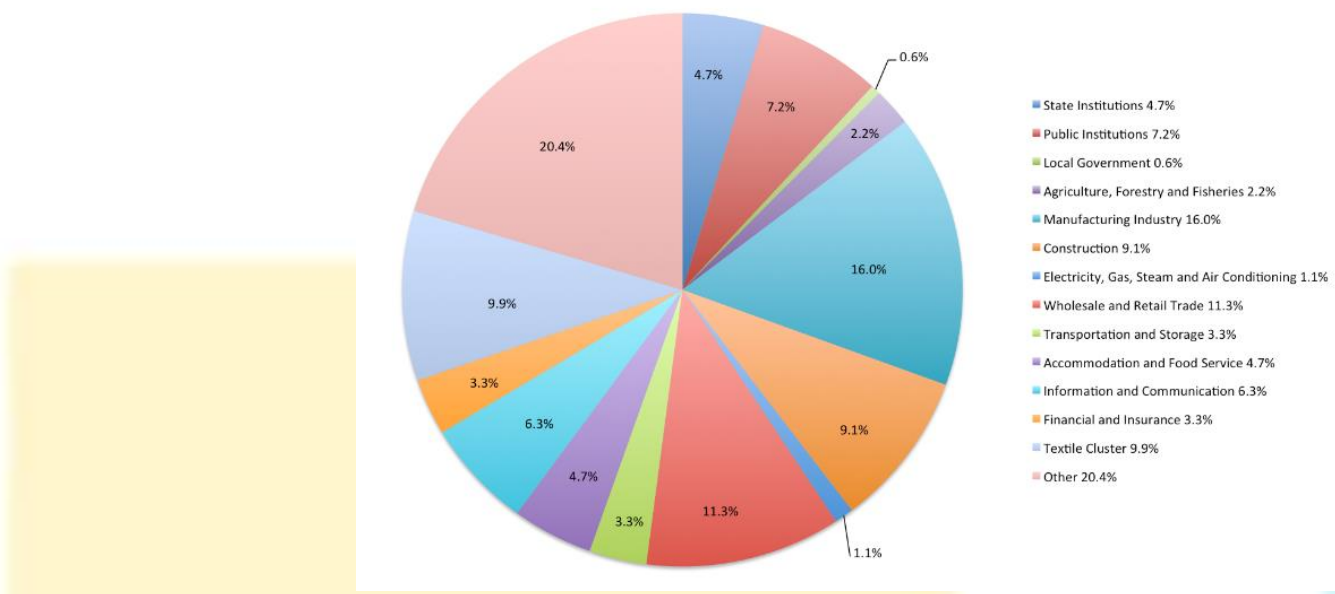

Fig 1: The participation of the companies in the research through percentages, divided according to their economic branches

\subsection{Is there interest in Macedonian companies to learn?}

A several questions were asked in order to get a clear picture of Macedonian companies and their interest to learn and encourage individual and collective learning who would promote the business results. Does Macedonian companies practice on-the-job training as well as training for acquiring additional knowledge?

This question was answered by 363 companies and the following data was obtained:

- $36,6 \%$ of respondents have planned, organized and conducted training;

- $34,7 \%$ of respondents said they sometimes practice on-the-job training;

- $16 \%$ of them never practice training;

- $12,7 \%$ of respondents said that the training is mandatory when new technology is introduced.

The results of the survey showed that most of the training programs are conducted by the companies themselves.

The need to raise the qualification level of employees is particularly important in terms of investment in modern technology. The experience in Macedonia has shown necessity of continuous training for workers especial training programs which comply with the EU requirements.

The question whether the company has regular training for acquiring additional knowledge is asked in order to investigate the awareness of top management, the need for continuous professional development and employee development in the era of knowledge, where continuous staff training is imperative for competitiveness and further development .The survey gave the following results:

- $49,9 \%$ of respondents have training for acquiring additional knowledge upon request without prior planning;

- $31,1 \%$ of respondents have training for acquiring additional knowledge continuously throughout the year;

- $10,5 \%$ of them don't practice additional training;

- $4,7 \%$ have training once a year;

- $3,9 \%$ of them attended training twice a year, which is the minimum requirement for professional development in the era of knowledge.

Worries the fact that $10.5 \%$ of the surveyed companies do not practice training for acquiring additional knowledge. Permanent, continual training is a requirement for survival in the modern business. These real indicators show that the lack of regular training for acquiring additional knowledge is one of the reasons for noncompetitiveness of Macedonian products on the global market.

Taking into account the fact that existing knowledge if not refreshed with new knowledge, will fade away in less than five years, raised the question on how competent are the employees (38 organizations) that do not practice improvement of knowledge and how they are meeting the needs of modern business management.

If we look at the practice of regular training for acquiring additional knowledge per industries, we will get the following results (see Figure 2): 


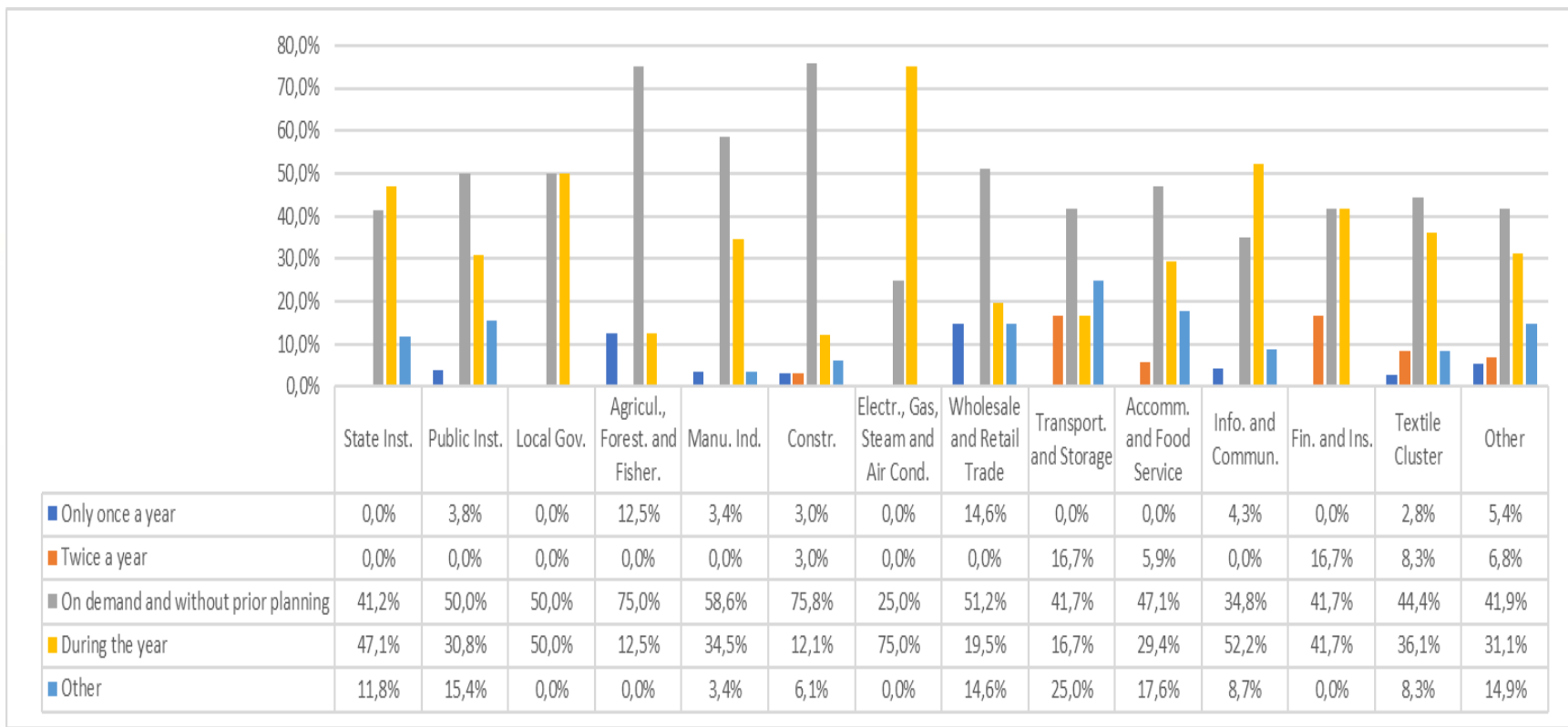

Fig 2: Acquiring additional knowledge in the companies per industry

The practice of regular training for acquiring additional knowledge is better in the sectors of financial activity, sales and retail where they organize training twice a year. In these industries changes in legislation and market are imposing the need for continuous training and development of the competence of its employees. When it comes to the advancement of knowledge the worst situation in the construction, manufacturing, agriculture, transport and warehouse logistics.

Macedonian companies have not yet realized the necessity of advancing knowledge as a source of competitiveness, the condition for survival in the market and driving force for further development. All this requires additional effort which is based on strong leadership and participation of all employees (readiness of cooperation and teamwork, which does not suffocate the creativity and individualism).

Among the many problems that Macedonian companies are facing is the insufficient education of the top management. Nowadays, we have top managers who were educated in the old system and they do not accept the changes of the new era. Companies are working without vision for the future which brings difficulties in adapting to the needs of buyers/users.

If managers have a vision where the global economy is moving, which is what customers demand from the product, it is certain that they can sort out all problems arising in the existence of Macedonian companies. Training of top management as the worldwide trend require and acquiring additional knowledge for proactive action will highly influence the success of the Macedonian companies.

To find out whether Macedonian companies are using consulting services for acquiring additional knowledge, the following question raised: Which areas have used such services?

- $47,4 \%$ of respondents do not use consulting services at all;

- $24,5 \%$ of respondents use consultancy services in introducing new technology for the needs of IT departments, human resources, marketing and other working units;

- $16 \%$ of them use consulting services for IT, human resources, as well as introducing new technology;

- $12,1 \%$ only when introducing new technology.

When analyzing the Macedonian companies for their effective cooperation with scientific - research, universities and other educational institutions in recent years, it was found that not only is low (only 18.8\%), but also those who already have some degree of cooperation it is considerably low or secondary developed. It is largely a consequence of insufficient understanding of companies for the services offered by these organizations and programs. Undisputed is the fact of our analysis that the issue of representation of the management hierarchy of the organization obtained a score of $3.5 \%$, indicating that many Macedonian companies have only one manager and others are direct reports. Due to poor management, there is a lack of time for managers and they do not show interest for cooperation that would give immediate results. The association of companies with scientific institutions will allow them to implement know-how, to gain basic knowledge, which includes education and training of high quality and effective implementation in the entire business and production practices. Macedonian companies that are not capable of learning and that are way behind on technological level, management style, innovation and quality of product and service, relations 
and employees culture must introduce learning to improve quality.

The new management system founded on TQM strategy requires less time and money and can have the same or greater effects as big investments in equipment. The solution can be found in the improvement of the quality through the use of the TQM strategy, development of staff, introducing learning to promote quality, improvement of processes prior to purchase of new technology. A proposed methodology of the subsystem education as one of the key pillars in the improvement of the quality through the application of the TQM strategy, is found in the succeeding pages.

\section{PROPOSED METHODOLOGY FOR THE SUBSYSTEM - EDUCATION}

The use of the integrated methodology for designing and implementing of TQM system must start with the education and therefore there should be well-organized subsystem of education in which companies can learn, easily adapt to the changes and use their knowledge for further development.

A complex system knowledge as per TQM should be spread from the head of the company - CEO to the immediate worker, with a different scope and load according to the various functions of operation the organization performs.

Planning of the educational process is task of the top management who is responsible to establish authority for education. Department of Education/Training and development department should draw up plans and programs for different levels of quality assurance, in compliance with the functions and duties of the companies using Deming's circle wheel of continual improvement.

Training and development department in its organization and methodology of work needs to meet the following obligations:

- identifying the need for education of employees according to the place, content and holders of positions in quality management;

- collaboration with experts and scientific researchers;

- building and establishing educational program;

- identifying, validating and implementing the concept of education;

- developing and implementing motivational activities in educational quality system of the company;
- continual improvement of employee knowledge system as a condition for the quality system.

Department of Education should prepare a variety of programs - for different levels of quality management, differentiated according to the basic levels of the organizational structure.

Training as per the organizational structure includes implementation of the following steps (Mitreva, 2012)[12]:

\section{$>$ Step 1: Education on strategic management.}

Education on strategic management is performed through the school of quality or creative workshops for quality where attendants will be introduced to: philosophy of the system for total quality management - induction for the top management; interpreting the circle of quality and TQM philosophy, training of methods and techniques for impeccable operation and training for optimization of business processes.

$>$ Step 2: Education on tactical and / or operational management for quality management.

Forms of education for the management of this level are quality schools and workshops on quality. The program refers to the detailed elaboration of the problems of management and quality control.

$>$ Step 3: Education of employees in various sectors (departments/divisions).

The content of this program should provide knowledge of the essence and philosophy of TQM, the methodology of the quality system and in particular to gain operational knowledge for achieving the quality system. Employees through quality workshops are trained on the following topics: training for the implementation of business processes; training for applying the methods and techniques of SPC in the workplace (checklist, dispersion analysis, regression and correlation, planned experiment Taguchievata formula, etc.); on-the-job training - there is a need of training until the employee does not achieve working results which are within the limits of statistical process control; training defined by the legislation; incentive to all for further education as well as serving as an example. In addition, employees must be trained and motivated to learn from others, to intent to upgrade their knowledge and experiences.

The process of education should happen through the application of circle of quality which can be described in a form of block diagram as shown on Figure 3. 


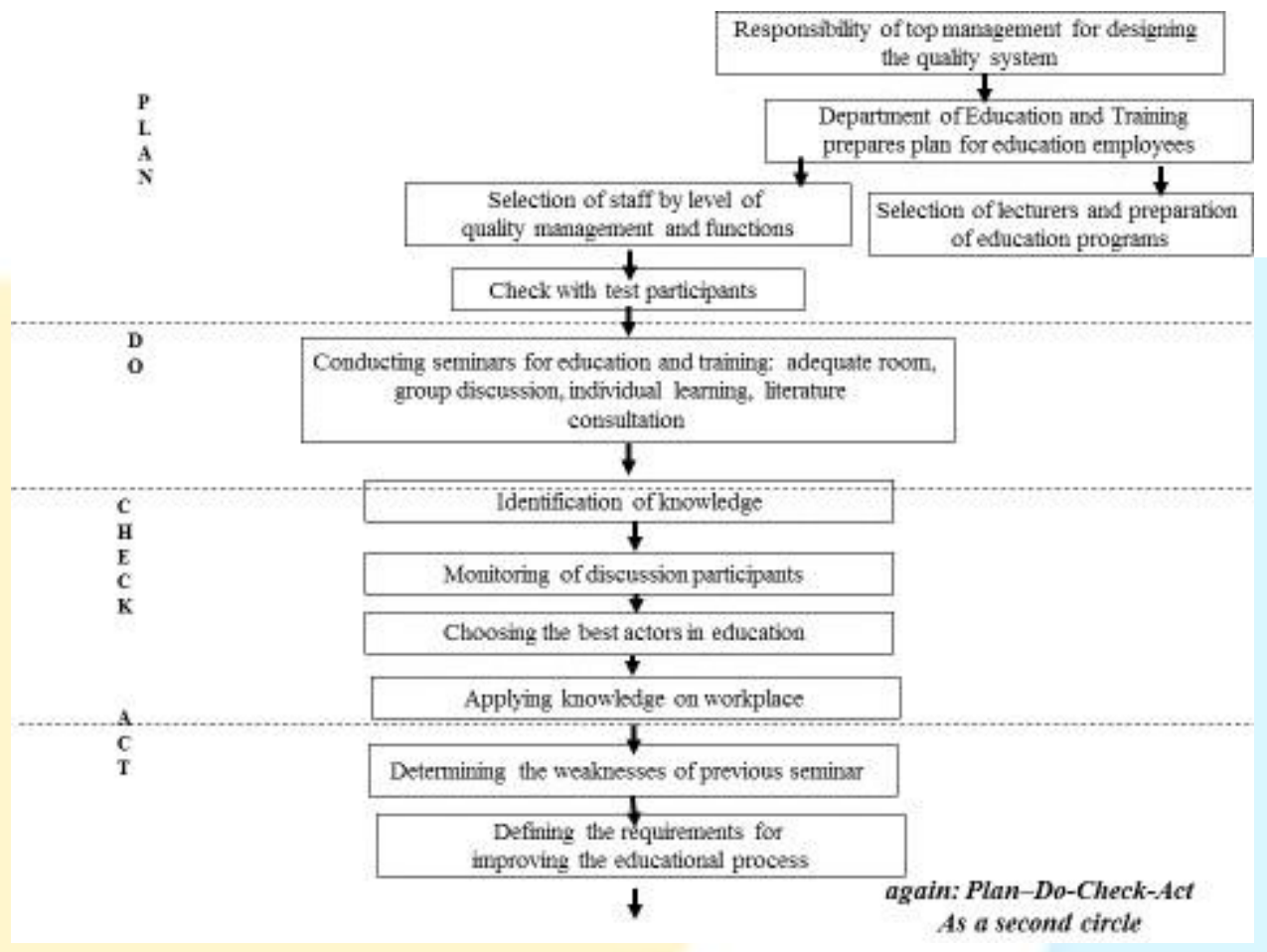

Fig 3: Proposed methodology for the subsystem - education

The management of the company is obliged to provide all conditions for successful implementation of education programs and it requires detailed elaboration, finding the best answers to the questions what, who, whom, when, where and how in the hierarchy of the company to be acquired with the knowledge of quality assurance.

In the planning stage of the educational process the following steps should be performed:

$>$ (Plan) Step 1: Plan for education of employees.

Department of Education prepares a plan for the education of employees.

$>$ Step 2: Selection of trainers (experts, specialists) from within the company or external to deliver the training.

External education can be realized under the supervision of external experts especially for the TQM philosophy, which through specialized programs, seminars and trainings will bring experience from developed countries in the world. This kind of education will bring new knowledge that will stimulate the creativity of employees. Internal education is done through workshops which are attended by 5-15 employees, under the supervision of expert who knows the problems of the company, who can reveal the causes of the problems, weaknesses, mistakes, will propose new measures to improve and preventive measures.

$>$ Step 3: Selection of training participants from employees in different sectors.
The selection of participants is based on a separate survey and testing. The method of surveying, defining questions, processing of results and the actual selection should be done by competent professionals and institutions.

\section{$>$ (Do) Step 4: The actual training.}

Training should be conducted in the premises of the company, using auxiliary teaching and monitoring resources and in secure working environment. The quality of the transferring of knowledge will depend on the knowledge and skills of the trainers, the interest of the trainees, the available literature, the monitoring resources etc., but mostly of the interaction between trainers and participants. Significant factors for quality assurance in education are: working conditions; motivation; consistency at work and responsibility.

\section{$>$ (Check) Step 5: Knowledge assessment.}

Assessing the knowledge of participants in the education and their active participation in it, it is an integral part of quality education. It shall include: questions, exams, open discussions - as the first part of the testing, with assignment of tasks at the workplace - as a second practical part of the education process. Knowledge assessment is used for testing the accomplishment of the trainers; implementation of educational programs and the capacity of participants in education. These results are used not only for the final evaluation of the effectiveness of the training, but also for taking corrective measures to further improve the quality of the educational process of the company. 


\section{$>$ (Act) Step 6: Modifying the program for education and training.}

Modification is an important activity in the educational process. It is implemented based on the evaluation of the success of the former workshop. Modifications are usually referred to the choice of trainers; content of the program; engagement activities throughout the course; training environment and so on.

Having determined deficiencies, the corrective measures will apply to eliminate them, to ensure the quality of education is as planned. With the modifications the second round of quality may start (Plan-Do-Check-Act). This work style continues in circle in the direction of continuous improvement in all functions of the company's operations.

\section{CONCLUSION}

The use of this draft methodology in Macedonian companies is not an easy task but a barrier that must be bridged without presuming that someone else will do it. The practice of this methodology will allow companies to foster regular training for all employees, thereby creating environment for employees to easily accept changes, to easily adapt to new conditions, to successfully manage business processes and functions, and with it to contribute to escalation of the competitive advantage of the company on the market.

\section{Acknowledgement}

This study is a part of the research project "Developing a model for performance improvement of business processes by an application of benchmarking strategy based upon examples of innovation", (Ref. No. 171395/1).

\section{REFERENCES}

[1] Bohdanowicz, P., Simanic, B., \& Martinac, I. (2005). Environmental training and measures at Scandic Hotels, Sweden. Tourism Review International, 9(1), 7-19.

[2] Chepujnoska, V., \& Chepujnoski, G. (1993). Quality Management Basics. Faculty of Economics, Skopje, 41-159.

[3] Deming, W. E. (2000). The new economics: for industry, government, education. MIT press.

[4] Drucker, P. (2014). Innovation and entrepreneurship. Routledge.

[5] Davenport, T. H., \& Prusak, L. (1998). Working knowledge: How organizations manage what they know. Harvard Business Press.

[6] Drew, S. A., \& Smith, P. A. (1995). The learning organization:"change proofing" and strategy. The Learning Organization, 2(1), 4-14.
[7] Edvinsson, L., \& Malone, M. S. (1997). Intellectual Capital: Realizing Your Companyl's True Value by Finding Its Hidden Brainpower.

[8] Edvinsson, L., \& Sullivan, P. (1996). Developing a model for managing intellectual capital. European management journal, 14(4), 356-364.

[9] Garavan, T. N. (1991). Strategic human resource development. Journal of European Industrial Training, 15(1).

[10] Jashapara, A. (2003). Cognition, culture and competition: an empirical test of the learning organization. The Learning Organization, 10(1), 3150.

[11] Kaplan, R. S., \& Norton, D. P. (2004). Measuring the strategic readiness of intangible assets. Harvard business review, 82(2), 52-63.

[12] Mitreva, E. (2012). The need for planning and implementing educational activities in Macedonian companies. International Journal for Quality Research, 6(2), 143-149.

[13] Medina-Muñoz, D., \& García-Falcón, J. M. (2000). Successful relationships between hotels and agencies. Annals of Tourism Research, 27(3), 737-762.

[14] Mumford, A., \& Gold, J. (2004). Management development: Strategies for action. CIPD Publishing.

[15] Prodanovska, V., \& Mitreva, E. (2009). Creating an innovative environment in total quality management system within companies. Perspectives of Innovations, Economics and Business, PIEB, (3 (3)), 86-88.

[16] Raidén, A. B., \& Dainty, A. R. (2006). Human resource development in construction organisations: An example of a "chaordic" learning organisation?. The Learning Organization, 13(1), 63-79.

[17] Robertson, M., \& O’Malley Hammersley, G. (2000). Knowledge management practices within a knowledge-intensive firm: the significance of the people management dimension. Journal of European Industrial Training, 24(2/3/4), 241-253.

[18] Symes, C., \& McIntyre, J. (2002). Working knowledge: The new vocationalism and higher education. McGraw-Hill Education (UK).

[19] Senge, P. M. (2014). The fifth discipline fieldbook: Strategies and tools for building a learning organization. Crown Business.

[20] Taskov, N., \& Mitreva, E. (2015). The motivation and the efficient communication both are the essential pillar within the building of the TQM (total quality management) system within the Macedonian Higher Education Institutions. Procedia-Social and Behavioral Sciences, 180, 227-234.

[21]Teare, R., \& Dealtry, R. (1998). Building and sustaining a learning organization. The Learning Organization, 5(1), 47-60. 